\title{
Effectiveness of Phosphodiesterase 5 Inhibitors in the Treatment of Erectile Dysfunction in Patients with Spinal Cord Trauma: Systematic Review and Meta-Analysis
}

\author{
Herney Andrés García-Perdomo ${ }^{a, b}$ Fernando Echeverría-Garcíac Aurelio Tobías ${ }^{d}$ \\ a Department of Urology, Universidad del Valle, Academic Managing Director Hospital Universitario del Valle, \\ ${ }^{b}$ Department of Epidemiology, Universidad Libre, and ' Department of Urology, University of Valle, Cali, Colombia; \\ ${ }^{d}$ Institute of Environmental Assessment and Water Research, Spanish Council for Scientific Research, Barcelona, Spain
}

\section{Key Words}

Spinal cord injuries · Phosphodiesterase 5 inhibitors .

Erectile dysfunction · Systematic review · Meta-analysis

\begin{abstract}
Objective:To determine the effectiveness of the Phosphodiesterase 5 (PDE5) Inhibitors for the treatment of erectile dysfunction in patients with spinal trauma. Methods: A systematic review and meta-analysis comparing PDE5 inhibitors versus placebo were carried out for clinical trials conducted between 1980 and 2014 that evaluated male patients older than 18 years, diagnosed with spinal cord trauma and erectile dysfunction. We designed a search strategy for Medline, CENTRAL, EMBASE and other electronic sources. Two investigators independently and blindly screened the studies for inclusion. A random effect meta-analysis was performed. Results: Six studies involving 963 patients were included. Male patients over 18 years with ED attributable or subsequent to traumatic spinal cord injury $(\mathrm{SCl})$ were included from these studies. In 4 of these studies, patients were randomized to the treatment group receiving sildenafil and the comparison group was placebo. Out of the remaining 2 trials, one compared tadalafil against the placebo and the other vardenafil
\end{abstract}

\section{KARGER}

๑) 2016 S. Karger AG, Basel

E-Mail karger@karger.com

www.karger.com/uin versus placebo. The improvement on SCls with PDE5 inhibitors was found to be large (standardized mean difference $0.71 ; 95 \% \mathrm{Cl} 0.39-1.03)$, with a high heterogeneity $\left(\mathrm{I}^{2}=\right.$ 74.4\%). Conclusions: PDE5 inhibitors are effective for the treatment of erectile dysfunction secondary to $\mathrm{SCl}$.

(c) 2016 S. Karger AG, Basel

\section{Introduction}

Spinal cord injury (SCI) is a public health problem that primarily affects patients of working age (55\%), producing a negative impact on the quality of life [1]. In the United States, the annual incidence and the prevalence are estimated between 130 and 1,124 cases per million people and $11.5-53.9 \%$, respectively [2], and it is one of the most important causes of erectile dysfunction in men under 40 years [3]. SCI constitutes an absolute limitation for the development of sexuality, erection and fertility. It is now considered that the lack of sexual motivation is associated with social isolation and limitation for rehabilitation. Sixty-six percent of patients with spinal cord trauma consider their erection sufficient to perform sexual intercourse, although both men and women report low fre-

Assist. Prof. Herney Andrés García-Perdomo, MD, MSc, EdD, PhD 
quency sexual activity $[1,3]$. In men with complete SCI, more than $80 \%$ can achieve erection, whether reflexogenic, psychogenic or mixed; however, most of them require some kind of treatment for erectile dysfunction. Meanwhile, in patients with incomplete injuries, a large proportion of them also require treatment [4].

Phosphodiesterase 5 (PDE5) inhibitors have been extensively studied in the context of erectile dysfunction. At present, 3 drugs of this group are available for commercial use: sildenafil, tadalafil and vardenafil. They act by a selective blocking of the enzyme PDE5, which catalyzes the hydrolysis reaction of cGMP making GMP; accordingly, the blood flow is increased cavernous through smooth muscle relaxation, which prolongs the erectile function (EF) [2]. PDE5 inhibitors represent a safe and well-tolerated strategy in the management of erectile dysfunction secondary to SCI [5], as described in a systematic review developed by DeForge et al. [6]. Although, it included observational studies, it stated that these interventions could affect sexual activity positively in SCI patients.

We aimed to determine the effectiveness of the PDE5 inhibitors for the treatment of erectile dysfunction in patients with SCI.

\section{Methods}

A systematic review and meta-analysis of randomized clinical trials conducted on male patients older than 18 years and diagnosed with spinal cord trauma and secondary erectile dysfunction was performed. We investigated the efficacy of PDE5 inhibitors in comparison with placebo or no intervention, considering the erectile dysfunction measured by international index of EF (IIEF) as primary outcome. Studies without the assessment of effectiveness or erectile dysfunction were excluded.

\section{Procedures}

We designed a search strategy for studies published in Medline via PubMed, CENTRAL and EMBASE (last search 05/2016). The search strategy was specific for each database and included a combination of the medical subject headings and free text terms for the condition of interest. No language or publication status restrictions were present. We included studies conducted and/or published between 1980 and 2016. The full search strategies are reported in online supplementary eAppendix 1 (see www.karger. com/doi/10.1159/000448290). The results of searches were crosschecked in order to eliminate duplicates. Two investigators independently and blindly screened the titles and abstracts to determine the potential usefulness of the articles. Eligibility criteria were applied to the full-text articles during the final selection. When discrepancies occurred, an agreement was charted out to make a final decision. No language restrictions were imposed. Data were collected using a standardized data extraction sheet, which contained study design, methods, participants, and outcome details.
Reviewers confirmed all data entries and checked at least twice for completeness and accuracy.

The risk of bias was ascertained with the Cochrane Collaboration instrument [7]. This instrument assesses the description and suitability of 7 domains: sequence generation, allocation concealment, blinding of participants and personnel, blinding of outcome assessment, incomplete outcome data, selective outcome reporting, and other sources of bias. Some domains are assessed at study and the remaining ones at the outcome level. A judgment on the risk of bias for each entry is given in terms of low, high, or unclear risk.

\section{Statistical Analyses}

Effect sizes were calculated as follows: standardized mean differences (SMDs) were calculated for continuous outcomes and ORs for dichotomous ones. SMDs were subsequently re-expressed as OR to allow further combination of continuous and dichotomous outcomes [8]. An SMD of 0.2 was considered small, of 0.5 moderate, and 0.8 large [9]. Studies comparing 2, or more, IIEF scales for erectile dysfunction were combined in a one single effect estimate. Between-study heterogeneity was assessed using Cochran's Q test [10] jointly with the $\mathrm{I}^{2}$ index [11], which enables the percentage of variation in the combined estimate that can be attributed to heterogeneity to be established ( $<25 \%$ : low heterogeneity; $25-50 \%$ : moderate; $50-75 \%$ : high; $>75 \%$ : very high). The study-specific estimates were pooled using a random effects model by means of the inverse variance method in the presence of statistical heterogeneity, and using a fixed effects model otherwise. Additional sub-group meta-analysis was conducted by the type of PDE5 inhibitors. Analyses were conducted using Stata statistical software, release 12 (StataCorp, College Station, Tex., USA).

This study was registered with the international prospective register of systematic reviews (PROSPERO): CRD42014010477.

\section{Results}

\section{Description of Studies}

Six studies out of 57 conducted with the search strategies designed, were finally included in the review (fig. 1). Overall, 963 male patients over 18 years with ED attributable or subsequent to traumatic SCI were included in these studies (table 1). In 4 of these studies, patients were randomized to the treatment group receiving sildenafil (Viagra), usually in doses ranging between 50 and $100 \mathrm{mg}$. The comparison group was placebo [12-15]. The remaining 2 trials did compare tadalafil, 10-20 mg dose [16], and vardenafil, 5-20 mg dose [17], both versus placebo.

Overall, all studies included patients older than 18 years, except for Khorrami et al. [15] that included patients aged 44-55. Sample size ranged from 26 [13] to 418 patients [16]. Efficacy of treatment was determined by using different instruments in each study: the IIEF 3 and 4 questionnaires [12]; the Global Efficacy Assessment (GEA) questions 3 and 4 [13]: the GEA question 1 [14]; 


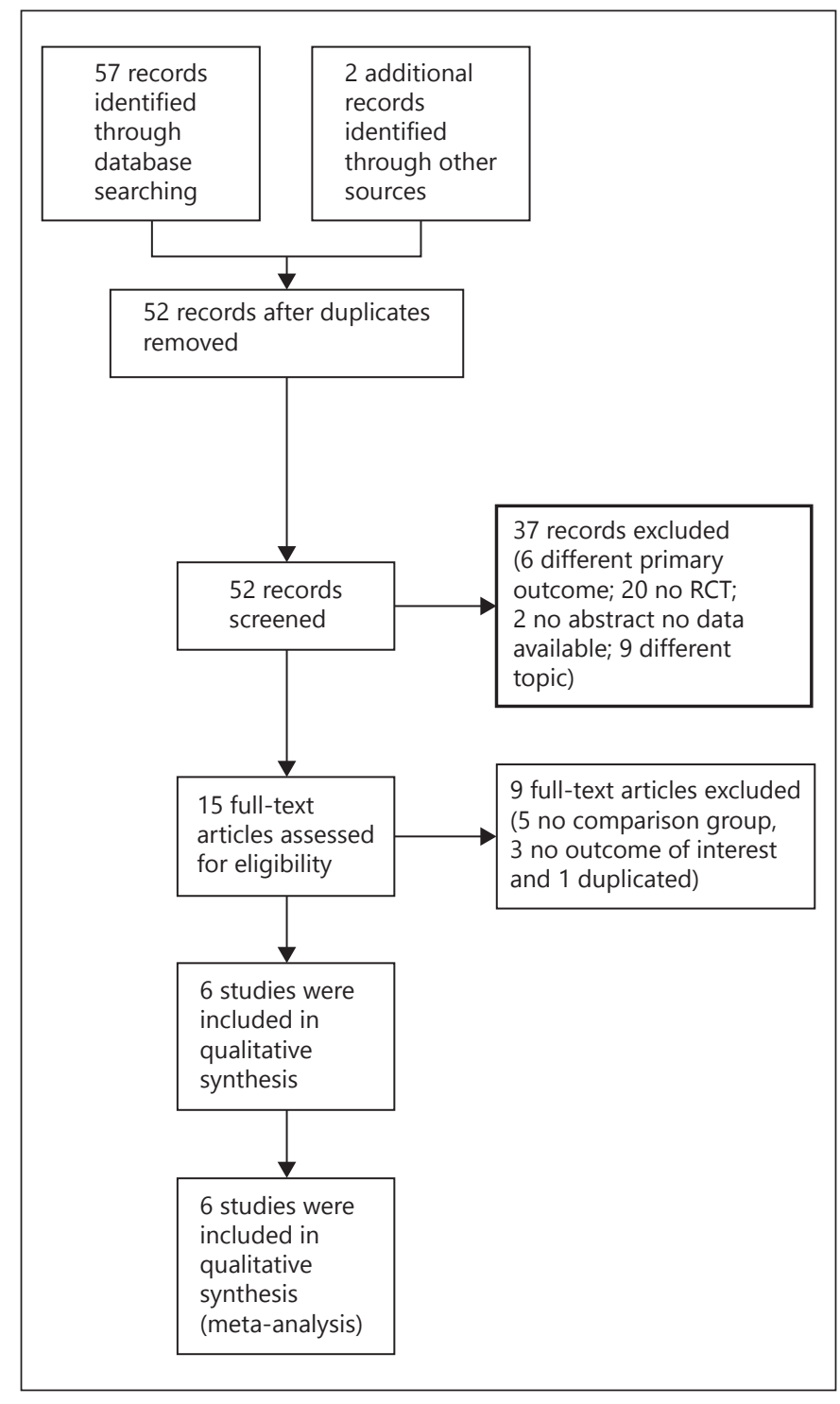

Fig. 1. Flowchart of study selection.

the IIEF5 questionnaire [15]; the IIEF questionnaire, the EF domain and the sexual encounter profile (SEP) questions 2 and 3 (SEP) [16]; and the IIEF-EF questionnaires and responses to the SEP questions 2 and 3 [17].

\section{Adverse Effects}

Khorrami et al. [15] found 8 patients with headache, 4 patients with flushing and gastrointestinal discomfort in 3 patients [15]. Ergin et al. [14] only described that there were no differences between groups $(p=0.19)$. In Maytom et al. [13], 15 patients experienced any kind of adverse effects in the sildenafil group and 12 patients in the placebo group (mostly headaches) [13].
Giuliano et al. [16], found 29 patients with adverse effects in the tadalafil group compared to 5 patients in the placebo group (mainly headaches). In Giuliano et al. [17], 61 patients experienced any adverse effect in the vardenafil group versus 18 patients in the placebo group (primarily headaches and flushing). Giuliano et al. [12] showed 54 patients with any adverse effect in the sildenafil group compared to 10 patients in the placebo group (mostly headaches and flushing).

\section{Risk of Bias}

According to the Cochrane risk of bias tool, the study by Khorrami et al. [15] had unclear risk of selection bias, since neither the random sequence generation nor the allocation concealment was clearly explained. In addition, the method used to blinding the subjects and personnel is not fully explained, and also the outcome assessment, which is similar to the Ergin's study [14]. Two of the studies of Giuliano et al. $[16,17]$ had high risk of attrition bias since many patients discontinued the assigned treatment. Similar to the studies of Maytom et al. [13], Ergin et al. [14] and Khorrami et al. [15], there was an unclear risk of selection, performance and detection bias in the studies. On the other hand, the first study by Giuliano et al. [12], had a high risk of selection, performance and detection bias since authors could easily know the randomization and blinding codes (fig. 2).

\section{Efficacy of PDE5 Inhibitors}

Figure 3 shows the effect of PDE5 inhibitors compared with placebo from a meta-analysis through a random effects model. The improvement on SCIs with PDE5 inhibitors was found to be large (SMD 0.71; 95\% CI 0.39-1.03) with a high heterogenerity $\left(\mathrm{I}^{2}=74.4 \%\right)$. The results stratified by the type of drug are shown in table 2. The effect of sildenafil, compared with placebo, from a random effects meta-analysis was found to be the largest (SMD 1.05; 95\% CI 0.36-1.73, $\mathrm{I}^{2}=82.5 \%$ ). Tadalafil compared with placebo showed a moderate effect (SMD 0.55; 95\% CI 0.35-0.75), while the effect of vardenafil was a small effect (SMD 0.35; 95\% CI 0.130.57). However, these last comparisons were based only on a single study.

\section{Discussion}

Six studies were included in qualitative and quantitative analyses. Nine hundred sixty three patients were included in all studies [12-17]. The overall efficacy of PDE5 
Table 1. Characteristics of included studies

\begin{tabular}{|c|c|c|c|c|c|c|}
\hline $\begin{array}{l}\text { Khorrami et al. } \\
{[15], 2010}\end{array}$ & Iran & $\begin{array}{l}\text { Sildenafil }(\mathrm{n}=59) / \\
\text { placebo }(\mathrm{n}=46)\end{array}$ & $\begin{array}{l}\text { Superior and inferior } \\
\text { motoneuron injury }\end{array}$ & Sildenafil 50 mg PO & Placebo & IIEF \\
\hline $\begin{array}{l}\text { Ergin et al. } \\
{[14], 2008}\end{array}$ & Turkey & $\begin{array}{l}\text { Sildenafil }(n=24) / \\
\text { placebo }(n=26)\end{array}$ & $\begin{array}{l}19 \text { years of age or older } \\
\text { with a diagnosis of } \\
\text { traumatic SCI at least } \\
6 \text { months before screening }\end{array}$ & $50 \mathrm{mg}$ sildenafil PO & Placebo & $\begin{array}{l}\text { GEA; IIEF; } \\
\text { EDITS scores }\end{array}$ \\
\hline $\begin{array}{l}\text { Giuliano et al. } \\
{[16], 2007}\end{array}$ & $\begin{array}{l}\text { France, } \\
\text { Germany, } \\
\text { Italy, Spain }\end{array}$ & $\begin{array}{l}\text { Tadalafil }(\mathrm{n}=142) / \\
\text { placebo }(\mathrm{n}=44)\end{array}$ & $\begin{array}{l}18 \text { years or older with ED. } \\
\text { Any spinal level and } \\
\text { neurological impairment } \\
\text { and that occurred at } \\
\text { least } 6 \text { months before }\end{array}$ & $\begin{array}{l}10 \mathrm{mg} \text { tadalafil } \\
\mathrm{PO} / 20 \mathrm{mg} \text { tadalafil } \\
\mathrm{PO} \text { after the first } \\
\text { week of follow-up }\end{array}$ & Placebo & IIEF; SEP \\
\hline $\begin{array}{l}\text { Giuliano et al. } \\
{[12], 1999}\end{array}$ & $\begin{array}{l}\text { Europe, } \\
\text { Australia }\end{array}$ & $\begin{array}{l}\text { Sildenafil }(\mathrm{n}=175) / \\
\text { placebo }(\mathrm{n}=174)\end{array}$ & $\begin{array}{l}18 \text { years of age or older } \\
\text { who had sustained a } \\
\text { traumatic SCI at least } \\
6 \text { months before screening }\end{array}$ & 50 mg sildenafil PO & Placebo & IIEF; GEA \\
\hline $\begin{array}{l}\text { Maytom et al. } \\
{[13], 1999}\end{array}$ & England & $\begin{array}{l}\text { Sildenafil }(\mathrm{n}=13) / \\
\text { placebo }(\mathrm{n}=14)\end{array}$ & $\begin{array}{l}\text { Aged } 18 \text { years or older, a } \\
\text { documented history of SCI } \\
\text { (at least } 6 \text { months), solely } \\
\text { attributable to SCI }\end{array}$ & $50 \mathrm{mg}$ sildenafil PO & Placebo & GEA \\
\hline
\end{tabular}

inhibitors was SMD $0.71 ; 95 \%$ CI 0.39-1.03, with a high heterogeneity. PDE5 inhibitors selectively block the enzyme PDE5, which catalyzes the hydrolysis reaction of cGMP making GMP; accordingly, it prolongs EF [2]. PDE5 inhibitors have been studied in the context of erectile dysfunction in general patients [18] and in SCI, and they represent a safe and well-tolerated strategy in its management [5]. There are important and numerous articles supporting the effectiveness of PDE5 inhibitors in the treatment of ED in the general population with high heterogeneity [18]. On the other hand, there are only a few studies, mainly descriptive, some experiments and other reviews, suggesting the effectiveness in patients with this condition.

The effect of sildenafil compared with placebo, from a random effects meta-analysis was found to be large [1215]. This topic has been widely discussed in clinical practice; however, there was no clear statement about it. This paper remarks the importance of prescribing sildenafil to patients with SCI. Nevertheless, urologists must realize the variety of tests used to measure the outcome (IIEF- related tests, GEA and EDITS). This is according to the study of Jia et al. [19] who considered PDE5 inhibitors as the main option in SCI patients, mainly using sildenafil as we found. This SR shows the similarities among the different tools while we standardized them to find a more generalizable result.

The study of Ergin et al. [14] shows a very low effect inducing high heterogeneity. If this study is removed, the effect would be consistent, but the heterogeneity will be lowered, which is important for assessing the real effect and for generalizing the results among the SCI population.

Tadalafil compared with placebo showed a moderate effect, while the effect of vardenafil was small. The last comparisons were based only on a single study $[16,17]$ because of which the results cannot be generalized in the SCI population; this is a serious limitation. The improvement with tadalafil was based on IIEF-EF, SEP2 and 3 scales. We found flaws in the quality assessment by the Cochrane risk of bias tool and high statistical heterogeneity. Regarding vardenafil, we found high heterogeneity 


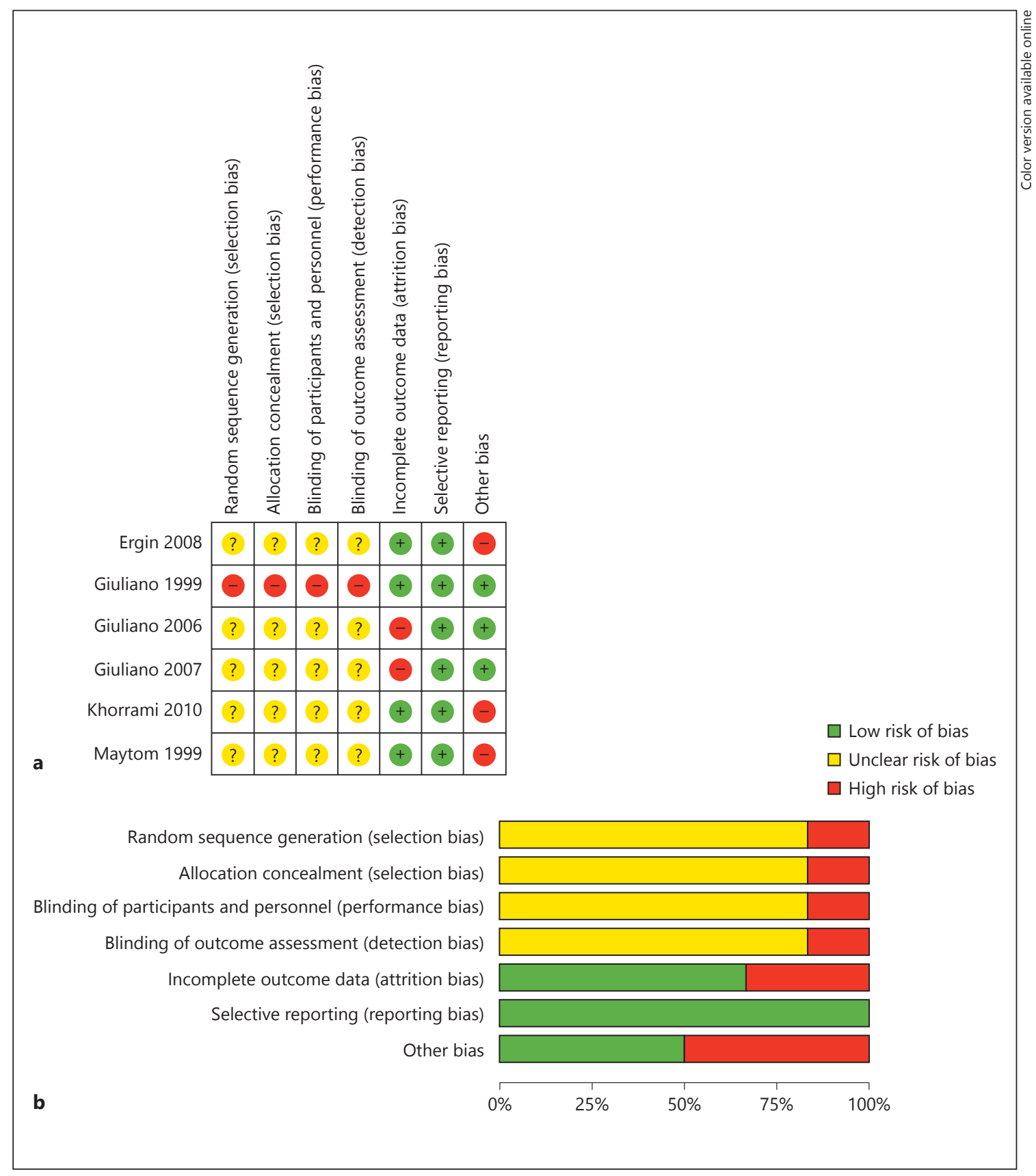

Fig. 2. Risk of bias within studies (a) and across studies (b).

on the scales used (IIEF-EF, SEP2 and 3). There was also unclear and high risk of bias in most of the items of the Cochrane tool. This agrees with the published literature.

Four studies described the efficacy of sildenafil, one showed the efficacy of vardenafil and the other one talked about tadalafil. All of them have the same pharmacologic mechanism. Sildenafil is the most frequently used PDE5 inhibitors in the general and in SCI populations, which could explain partly, the higher effect from sildenafil. Besides, we lack studies from the other 2 PDE5 inhibitors.

The positive effect is consistent among the 3 PDE5 inhibitors, so people with this condition could use them for treating ED, especially sildenafil. In contrast, we lack evidence to support the use of PDE5 inhibitors in patients 


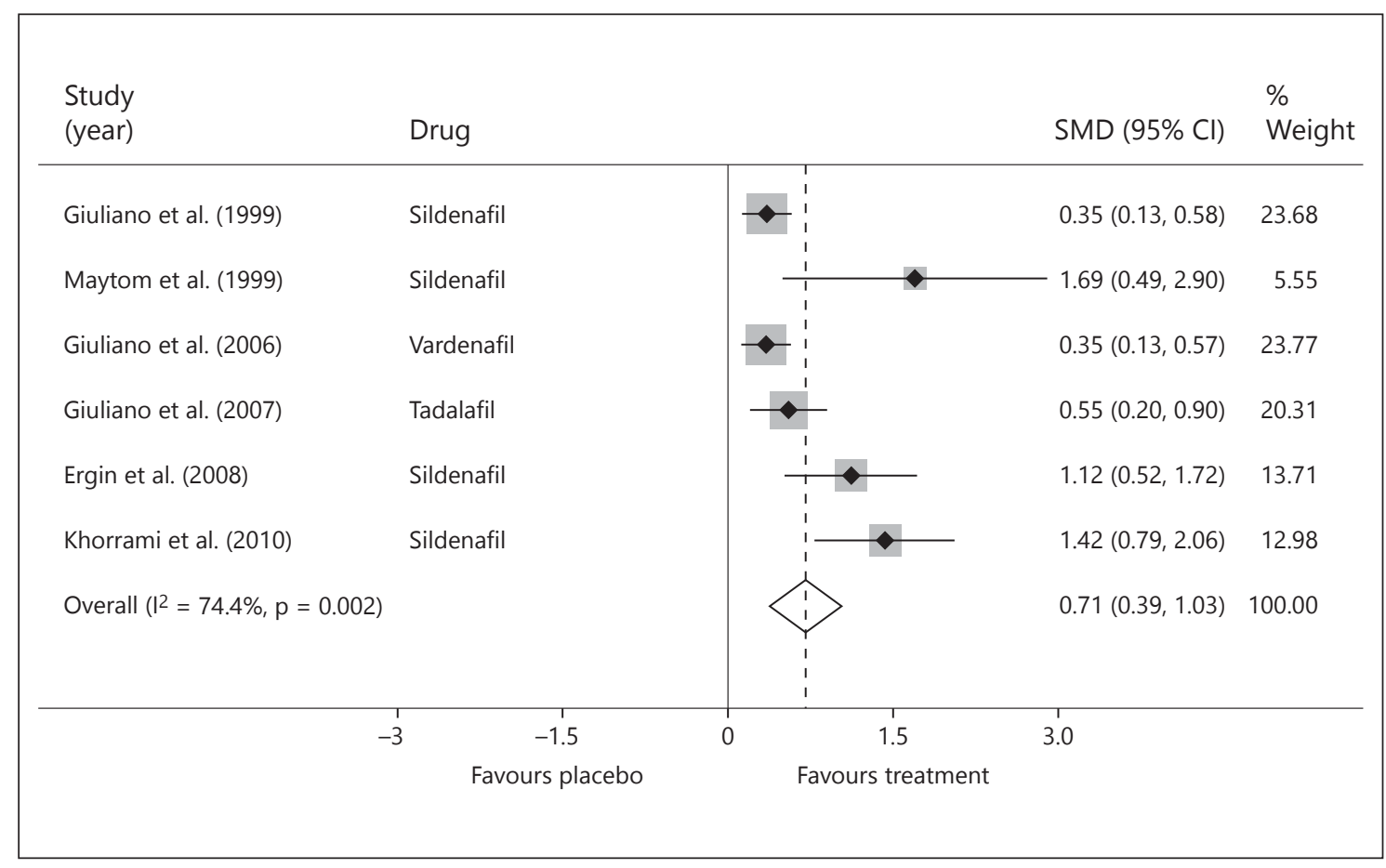

Fig. 3. Forest plot of the comparison of PDE5 inhibitors versus placebo for the efficacy on SCI.

with multiple sclerosis or any other central nervous system disturbance, since studies are scarce and lack good quality [20, 21].

Regarding adverse effects, we found high heterogeneity describing this aspect on different studies; however, it was important to see that the most frequent ones were headache and flushing, according to literature related to the general population and SCI $[18,19]$.

Finally, we would like to mention here that there are other important tools that the urologists have on their hands (vaccum, papaverine, prosthesis, among others); however, these other tools lack evidence that supports their use in this population [22].

\section{Limitations}

There was high heterogeneity that could be explained by studies with a low sample size and the variety of scales used to measure the outcome. The use of different tools represents a problem at the moment of the interpretation in a clinical context.

In a broad vision, looking at the risk of the bias table across studies, we noticed that the studies have flaws on the quality in almost all areas, mainly in patient selection, blinding and outcomes data (except in reporting bias). These findings limit the stated conclusions.

Effectiveness of PDE5 Inhibitors in the Treatment of Erectile Dysfunction
Table 2. Subgroup meta-analysis by type of PDE5 inhibitor for the efficacy on spinal cord injury

\begin{tabular}{lllll}
\hline Drug & Number & SMD & $95 \%$ CI & $I^{2}, \%$ \\
\hline Sildenafil & 4 & 1.05 & $0.36-1.73$ & 82.50 \\
Tadalafil & 1 & 0.55 & $0.35-0.75$ & - \\
Vardenafil & 1 & 0.35 & $0.13-0.57$ & - \\
\hline
\end{tabular}

$\mathrm{I}^{2}=$ Index of heterogeneity.

\section{Conclusion}

PDE5 inhibitors are effective for the treatment of erectile dysfunction secondary to SCI; however, we must attempt to better design randomized controlled trials and standardize the best tool to assess EF.

\section{Author's Contribution}

F.E.-G. and H.A.G.-P. conceived the study, performed the literature search, data extraction, analysis, quality assessment and contributed on writing the manuscript; A.T. contributed with data analysis and writing the manuscript; all authors provided input to the critical review of the manuscript. 


\section{References}

1 Acevedo GJ, Varón LF, Berbeo CM, Feo LO, Días OR: Avances fisiopatológicos para el entendimiento de la lesión medular traumática. Revisión bibliográfica. Rev Col Or Tra 2008; 22:272-281.

2 Rizio N, Tran C, Sorenson M: Efficacy and satisfaction rates of oral PDE5is in the treatment of erectile dysfunction secondary to spinal cord injury: a review of literature. J Spinal Cord Med 2012;35:219-228.

3 Ludwig W, Phillips M: Organic causes of erectile dysfunction in men under 40 . Urol Int 2014;92:1-6.

4 Schmid DM, Hauri D, Schurch B: Nocturnal penile tumescence and rigidity (NPTR) findings in spinal cord injured men with erectile dysfunction. Int J Impot Res 2004;16:433440.

5 Lombardi G, Macchiarella A, Cecconi F, Del Popolo G: Ten years of phosphodiesterase type 5 inhibitors in spinal cord injured patients. J Sex Med 2009;6:1248-1258.

6 Deforge D, Blackmer J, Garritty C, Yazdi F, Cronin V, Barrowman N, Fang M, Mamaladze V, Zhang L, Sampson M, Moher D: Male erectile dysfunction following spinal cord injury: a systematic review. Spinal Cord 2006;44:465-473

7 O'Connor D, Green S, Higgins JPT (eds): Chapter 5: defining the review question and developing criteria for including studies; in Higgins JPT, Green S (eds): Cochrane Handbook for Systematic Reviews of Interventions. Version 5. The Cochrane Collaboration, 2011.

8 Schünemann HJ, Oxman AD, Vist GE, Higgins JPT, Deeks JJ, Glasziou P, Guyatt GH: Chapter 12: interpreting results and drawing conclusions; in Higgins JPT, Green J (eds)
Cochrane Handbook for Systematic Reviews of Interventions. Version 5. The Cochrane Collaboration, 2011

9 Higgins JPT, Deeks JJ, Altman DG (eds) Chapter 16: special topics in statistics; in Higgins JPT, Green S (eds): Cochrane Handbook for Systematic Reviews of Interventions. Version 5. The Cochrane Collaboration, 2011.

10 Cochran W: The combination of estimates from different experiments. Biometrics 1954; 10:110-129.

11 Higgins JP, Thompson SG, Deeks JJ, Altman DG: Measuring inconsistency in meta-analyses. BMJ 2003;327:557-560.

12 Giuliano F, Hultling C, El Masry WS, Smith MD, Osterloh IH, Orr M, Maytom M: Randomized trial of sildenafil for the treatment of erectile dysfunction in spinal cord injury. Sildenafil study group. Ann Neurol 1999;46: 15-21.

13 Maytom MC, Derry FA, Dinsmore WW, Glass CA, Smith MD, Orr M, Osterloh IH: A two-part pilot study of sildenafil (VIAGRA) in men with erectile dysfunction caused by spinal cord injury. Spinal Cord 1999;37:110116.

14 Ergin S, Gunduz B, Ugurlu H, Sivrioglu K, Oncel S, Gok H, Erhan B, Levendoglu F, Senocak O: A placebo-controlled, multicenter, randomized, double-blind, flexible-dose, two-way crossover study to evaluate the efficacy and safety of sildenafil in men with traumatic spinal cord injury and erectile dysfunction. J Spinal Cord Med 2008;31:522-531.

15 Khorrami MH, Javid A, Moshtaghi D, Nourimahdavi K, Mortazavi A, Zia HR: Sildenafil efficacy in erectile dysfunction secondary to spinal cord injury depends on the level of cord injuries. Int J Androl 2010;33:861-864.
16 Giuliano F, Sanchez-Ramos A, Löchner-Ernst D, Del Popolo G, Cruz N, Leriche A, Lombardi G, Reichert S, Dahl P, Elion-Mboussa A, Casariego J: Efficacy and safety of tadalafil in men with erectile dysfunction following spinal cord injury. Arch Neurol 2007;64:15841592.

17 Giuliano F, Rubio-Aurioles E, Kennelly M, Montorsi F, Kim ED, Finkbeiner AE, Pommerville PJ, Colopy MW, Wilkins HJ, Wachs $\mathrm{BH}$ : Efficacy and safety of vardenafil in men with erectile dysfunction caused by spinal cord injury. Neurology 2006;66:210-216.

18 Chen L, Staubli SE, Schneider MP, Kessels AG, Ivic S, Bachmann LM, Kessler TM: Phosphodiesterase 5 inhibitors for the treatment of erectile dysfunction: a trade-off network meta-analysis. Eur Urol 2015;68:674680 .

19 Jia DD, Shuang WB, Cheng T, Jia XM, Zhang M: Efficacy and safety of phosphodieterase-5 inhibitors for treatment of erectile dysfunction secondary to spinal cord injury: a systemic review and meta-analysis. Spinal Cord 2016;54:494-501.

20 Lombardi G, Musco S, Kessler TM, Li Marzi V, Lanciotti M, Del Popolo G: Management of sexual dysfunction due to central nervous system disorders: a systematic review. BJU Int 2015;115(suppl 6):47-56.

21 Xiao Y, Wang J, Luo H: Sildenafil citrate for erectile dysfunction in patients with multiple sclerosis. Cochrane Database Syst Rev 2012; 4:CD009427.

22 Lombardi G, Musco S, Wyndaele JJ, Del Popolo G: Treatments for erectile dysfunction in spinal cord patients: alternatives to phosphodiesterase type 5 inhibitors? A review study. Spinal Cord 2015;53:849-854. 